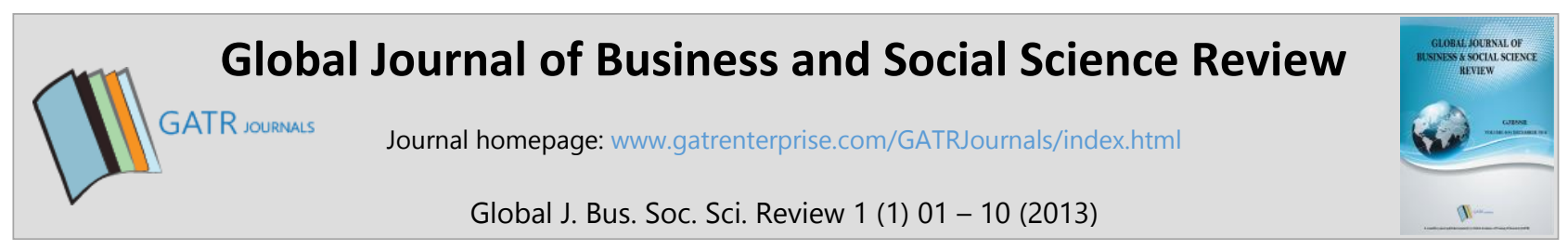

\title{
How to Mismanage Organisations: A Lawyer's Perspective
}

\author{
Gabriël A Moens* \\ Professor of Law and Director of Research, Curtin Law School, Perth, Australia and Emeritus Professor of Law, The University of \\ Queensland, Brisbane, Australia
}

\begin{abstract}
Objective: The purpose of this paper is to promote and to enhance sound management practices in organisations.

Methodology/Technique: In particular, this paper identifies four interrelated management practices which, in my experience, constitute 'mismanagement': (i) the appointment of managers to their level of incompetence (the Peter Principle), which in turn may lead to occupational stress and low staff morale, (ii) the appointment of employees who are deemed to be less 'intelligent' than, or 'inferior' to, the appointers, (iii) the centralisation of resources, services and decision-making by relevant organisations, arguably to improve efficiency and to achieve cost effectiveness, and (iv) constant restructuring of organisations and associated change management.

Findings: This paper focuses on actions or practices by senior management which may potentially result in the mismanagement of their organisations.

Novelty: It is not unusual for employees to allege that the organisations for which they work are mismanaged. Even if these allegations are unsupported, the fact that they are raised regularly justifies an examination of how organisations may be mismanaged.
\end{abstract}

Type of Paper: Conceptual

Keywords: Peter Principle; Hiring practices; Centralisation of resources; Restructuring, Change management. JEL Classification: L20, M10, M54.

\section{Introduction}

Here follows the further instructions for authors. It is not unusual for employees to allege that the organisations for which they work are mismanaged. Even if these allegations are unsupported, the fact that they are raised regularly justifies an examination of how organisations may be mismanaged.

During my career as a university academic and manager, and in other management roles, I have observed and experienced noted examples of mismanagement. Most examples of mismanagement discussed in this paper concern universities. However, my observations are equally applicable to, and valid for, organisations in general. Although my observations are largely based on my own knowledge and experience as an academic lawyer, they are supported by scholarly and empirical management research and informed by comparative

\footnotetext{
* Paper Info: Revised: December 2, 2012

Accepted: January 20, 2013

Corresponding author:

E-mail: gabriel.moens@curtin.edu.au

Affiliation: Professor of Law and Director of Research, Curtin Law School, Perth, Australia and

Emeritus Professor of Law, The University of Queensland, Brisbane, Australia
} 
analysis. The fact that I have worked in a number of non-academic organisations, including chambers of commerce, arbitration institutions, law firms and media organisations has provided me with the opportunity to compare different management approaches and styles. Mindful that "all judgment is comparative" (Johnson, Ch 30), a comparison of these different management approaches enables me to make a judgment as to what constitutes sound management practice.

This paper concentrates on four interrelated practices which, arguably, constitute 'mismanagement': (i) the appointment of employees to their level of incompetence (the Peter Principle), which in turn may lead to occupational stress and low staff morale, (ii) the appointment of employees who are deemed to be less 'intelligent' than, or 'inferior' to, the appointers, (iii) the centralisation of resources, services and decisionmaking by relevant organisations, and (iv) the constant restructuring of organisations and associated change management. I have selected these four mismanagement practices because, in my opinion, they are among the most egregious and misconceived practices. However, the actions which might result in the mismanagement of organisations are infinite and examples of other practices are also briefly reviewed in this paper.

\section{The Appointment of Employees to their Level of Incompetence}

\subsection{The Peter Principle}

A practice by senior management which may potentially result in the mismanagement of their organisations involves the appointment of employees to their level of incompetence which, in turn, may lead to occupational stress and low staff morale.

In their celebrated book The Peter Principle (later elaborated in the The Peter Prescription: How to Make Things Go Right and Why Things Go Wrong or the Peter Principle Revisited), Laurence J. Peter and Raymond Hull argue that "in a hierarchy every employee tends to rise to his level of incompetence" (at 7). From observation, the promotion of people to positions for which they are not properly prepared or for which their qualifications and experience are inadequate may generate occupational stress and low staff morale. The Peter Principle is not often linked to the literature of role-related stress, but it provides insights into how a mismatch of jobs and competencies acts as a stressor (El-Nadi, www.evancarmichael.com/HumanResources/840/Stress-and-Peter-Principle.html).

The Peter Principle is based upon the assumption that appointment of an employee to a higher-level position is a reward for excellence at the lower level. The appointee's incompetence usually only reveals itself after the employee has assumed the higher-level position. For example, a successful salesperson may be promoted to the position of divisional sales manager, and removed from the day-to-day sales activity, because of their ability to regularly exceed the sales target of the company. Also, the salesperson may be promoted with the intention that they will teach their sales techniques to the remaining staff, thereby boosting their performance. However, if the employee is promoted to their level of incompetence, the company may be forfeiting the income that otherwise would be generated by the excellent salesperson. Moreover, if the sales manager does not function effectively in their new management role, they may generate a stressful environment that infects the whole company. Common sense suggests, and experience confirms, that an ability to exceed the sales target is a poor indicator as to how well an appointee will do at the senior management level. In particular, it does not usually reveal the salesperson's capacity to manage staff or, indeed, their ability to impart their sales techniques to junior salespersons.

Another example, which is not uncommon in universities, is to appoint capable researchers or teachers to senior management roles, even the Vice Chancellor's or President's role. Indeed, even a perfunctory review of the Higher Education Supplement of The Australian reveals that the Australian university landscape is blighted by senior managers who, for a number of reasons (including a sense of self-importance, overstated confidence and/or arrogance or an inability to use 'power' wisely) are ultimately costly failures, even though they may have excelled in their previous roles (Forsyth, 36). 
The Peter Principle, although it is predominantly used to explain bad management decisions, is only an expression of a more general principle, namely that there is a tendency in society's endeavours for people to be pushed to their level of incompetence. For example, in an educational context, this principle can even be used for the purpose of evaluating preferential admission programmes in professional schools. These programmes, which commonly exist in universities in the United States, aim at increasing minority enrolment in professional schools. However, such a programme can be criticised on the ground that there can be no adequate numerical increase because it only pushes minority students from lesser to better (i.e. more prestigious schools with more demanding admission standards) schools (Moens, 470-477; Redish, 393-394). This phenomenon, which is known as the 'moving-up phenomenon', illustrates that each school, by its preferential admission, simply takes minority students away from other schools whose admission standards are further down the scale. Any net gain in the total number of minority students admitted must come, if it comes at all, from those schools the admission standards of which are at the bottom of the scale, and take students whom they would not otherwise have admitted. Hence, in this context, the implementation of the Peter Principle, as a more generalised principle which is not limited to the management of organisations, causes large numbers of minority students to attend schools whose normal admission standards they do not meet, instead of attending other schools whose normal standards they do meet (Summers, 384).

The Peter Principle does not indicate how an appointee to a position which exceeds their level of competence, could be removed from that position. Good management requires the development of pathways to enable people to be returned to their level of competence without substantial loss of face. In a recent interesting article, Carly Chynoweth provides examples of Chief Executive Officers who voluntarily relinquished their positions to return to their previously-held deputy position. She argues that this is not a retrograde step and does not constitute failure because there is a skill to lead from behind the curtain, certainly if this is more suited to the skills and goals of the relevant employee (Chynoweth, 2). However, in most cases the removal of incompetent employees who do not voluntarily return to their level of competence may be administratively very difficult, procedurally complex or prohibitively expensive. This is because the existence of numerous legal impediments and institutional procedural safeguards may actually prevent or complicate the removal of those who do not function effectively at the higher level.

Several matters that are not considered by the Peter Principle should be noted. The Peter Principle does not concern itself with the question as to why a capable and competent person may fail to advance in a hierarchical structure. Failure to advance in a hierarchical structure may be caused by the inability or unwillingness of management to recognise the assumed or perceived potential of an employee. This failure may be caused by jealousy or by the employee's lack of ambition, or by managers who have been promoted to their level of incompetence. Sometimes, persons in their early careers do not function optimally because they have not yet been able to marshal their potential talents. For example, young university teachers may not be the 'best' possible teachers they can be because of their lack of experience or confidence. However, they may later achieve excellent results once their potential is realised by working hard and diligently, developing maturity and even exploiting luck. The Peter Principle also does not deal with the interesting phenomenon, recognised by Roderick Swaab, that too much talent on a team often means that a team "performs worse overall" (Chynoweth, 3) and hence, a tipping point can be reached where decline sets in.

Instead, the Peter Principle explains why employees, who perform capably at a lower level, do not perform satisfactorily at a higher level. In essence, these employees cannot 'grow' in to their allocated task, but have nevertheless been appointed to perform it. Thus, the Peter Principle applies to a situation where employees are inherently unable to perform their job because of their incompetence, which in turn, is generated by mismatching appointees' qualifications, skills and experience, on the one hand, and the demands of the employee's occupational role, on the other. This mismatching constitutes a stressor, which causes occupational or role-related stress which is "an adaptive response to a situation that is perceived as challenging or threatening to the person's well-being" (McShane \& Travaglione, 202). 'Stress' has also been described as the "rate of wear and tear on the body caused by living" (Stone, 664). 


\subsection{The Peter Principle and the Management of Stress}

The professional literature regarding stress management deals extensively with the causes of stress, known as 'stressors' (Needham, 8-17; McShane \& Travaglione, 204-209). Stressors include, but are not limited to, interpersonal, organisational, physical, environmental and occupational factors.

The proposition that occupational stress may be caused by a mismatch of the professional role of employees on the one hand, and their qualifications and experience on the other, is instinctively perceived as valid. This is because employees are not expected to perform their tasks competently if their qualifications, skills and experience do not properly prepare them for the challenges of their professional role. The validity of this point is illustrated by McShane \& Travaglione who refer to a report produced by the New South Wales Law Society according to which more than half of the 1800 lawyers polled had been bullied or intimidated by clients. This bullying and intimidation caused severe occupational stress, which substantially decreased these lawyers' ability to function effectively in the legal profession (McShane \& Travaglione, 205). The situation described by these authors may occur, for example, if a successful black-letter lawyer, who performs brilliantly as a legal researcher in a law firm, is required to deal face-to-face with clients. The lawyer may be singularly deficient in their dealings with clients due to a lack of confidence, an inability to relate to people whose level of education may be minimal, or a failure to understand the 'end game' (i.e. the end result a client wishes to achieve). Ultimately, the stress experienced by these lawyers could be characterised as occupational stress which is caused by their inability to deal, or to communicate effectively, with their clients.

It is generally acknowledged in the managerial literature that occupational stress may be caused by a mismatching of the professional role assigned to an employee and their qualifications, skills and experience. For example, Lorraine Pirihi argues that "[s]tress is caused by many factors and often it's because the wrong people have been put into jobs that they are totally unsuitable for" (Pirihi: www.g55.in/businessfinance/article1606.html). She refers to a survey published in Forbes Business magazine which revealed that the prime cause of business failure in the United States is the appointment of people to jobs which they cannot competently perform. According to Raymond J Stone, the appointment of managers to their level of incompetence creates a vicious circle "as managers under stress ... produce stress in their subordinates and other managers" (Stone, 666). Stone also discusses an Australian study that establishes a link between role uncertainty and stress. It revealed among other things that $15 \%$ of managers did not know, or were unsure of, what was expected of them, and therefore could not know their goals and objectives (Stone, 668). Stone argues that in such situations, "managers are pressured to anticipate what their duties and responsibilities are, creating an internal fear that their actions are not appropriate and that they will be punished" (Stone, 668). The realisation that a mismatching of a person's professional role and their qualifications, skills and experience may result in occupational (role-related) stress has spawned an industry which aims at neutralising the deleterious effect of the Peter Principle in operation.

A review of the relevant literature also reveals that authors, in general, regard a limited amount of stress as necessary for the achievement of an employee's goals (Hanson, 15-19). As Stone argues, "When there is no stress, job challenges are non-existent" (Stone, 670). However, Stone also cautions that stress generated by information overload, working long hours and having to meet tight deadlines frequently may lead to burnout, thereby seriously affecting an employee's ability to achieve job satisfaction (Stone, 665). This phenomenon of 'burnout' is known in Japan as karōshi which means 'death from overwork' (McShane \& Travaglione, 207; Collins, 78). Similarly, John Message confidently states that, "Stress is a powerful servant but a tyrannical master. It can be a rich source of energy in the service of achievement and creativity; or it can be a source of corrosion and exhaustion" (Message, 6). Hence, from a management point of view it is necessary to ascertain at which point stress is likely to adversely affect an employee's ability "to feel a sense of achievement and to get satisfaction from the job" (Stone, 671). Occupational stress may thus have a positive effect and may even serve as a motivating force when employees' qualifications and experience match their occupational role, thereby enabling them to reach their potential. However, if a mismatch generates occupational stress, the consequences for the affected employee and the employer may be serious. 
The adverse effects of the application of the Peter Principle, especially the consequences of appointment to one's level of incompetence, can only be minimised by transferring employees "to jobs that better fit their competencies and values" (McShane \& Travaglione, 216). Of course, the allocation of employees to jobs that match their competences, skills and aptitudes requires a careful re-evaluation of the Peter Principle, the application of which is possibly the main role-related stressor resulting in an unhappy and demoralised workforce.

The literature also focuses on the impact of stress on managerial style, including the use by managers of their cognitive resources under stress. For example, Neil McAdam addresses the issue as to whether "stressful circumstances prompt a reversion to earlier less mature cognitive and expressive repertoires in the individual's attempt to manage the pressures of the noxious environment" (McAdam, 48). McAdam's observation, in effect, deals with the role played by 'emotional' intelligence to confront and resolve problems generated by incompetent management.

Peter Salovey and John D. Mayer have described 'emotional' intelligence as the "ability to monitor one's own and others' feelings and emotions, to discriminate among them and to use this information to guide one's thinking and actions" (at 189). They point out that, "The emotionally intelligent person ... attends to emotion in the path toward growth. Emotional intelligence involves self-regulation appreciative of the fact that temporarily hurt feelings or emotional restraint is often necessary in the service of a greater objective" (at 201).

In a revealing article, Leon Gettler describes the five categories of 'emotional' intelligence: (i) selfawareness ("understanding one's emotions and not letting feelings rule you"), (ii) self-regulation ("being able to control feelings and impulses"), (iii) motivation ("being highly productive and relishing a challenge"), (iv) empathy ("identifying with and understanding wants, needs and viewpoints of those around you"), and (v) social skills ("being an excellent communicator and a master at building and maintaining relationships") (Gettler, 11).

Gettler's five categories are certainly useful traits, possession of which might improve the performance of senior managers. Many intractable management problems occur because of senior managers who lack these traits. Some readers of this paper would probably be able to recall circumstances at work where high levels of stress were generated by people who were not able to control their emotions and, consequently, contributed to an explosive situation. This often involves screaming and yelling, the levelling of accusations (often in public) or the sending of obnoxious e-mail messages which make for horrifying reading. Thus, 'emotional' intelligence is directly related to the performance by managers of their duties. A lack of 'emotional' intelligence is a cause of mismanagement of organisations and, at the same time, a manifestation of managerial incompetence which, in turn, may have been instigated by the application of the Peter Principle.

\section{The Appointment of Employees who are deemed to be less 'Intelligent' than, or 'Inferior' to, the Appointers}

The robustness of an organisation could easily be eroded if senior management were to appoint employees, who are deemed to be less 'intelligent' than, or 'inferior' to, the appointers. This is a common occurrence in most organisations, and in my experience, is especially prevalent in universities. As a member of selection committees, I have often been appalled at the elimination of applicants whom I regarded as promising and enthusiastic. Instead, these committees often appointed applicants who, by all standards, would be unimaginative and ineffective and lack entrepreneurial flair, but would be compliant at all times and would slavishly implement the directives of senior management. Of course, this outcome may well be dependent upon the requirements for the role, and it should be recognised that the abilities that one person regards as making the candidate 'better' for the role may not be the abilities believed by other members of the selection committee as 'better' for the role.

The practice to appoint 'inferior' people may be explained by the fear of senior managers of being challenged by junior employees who are more intelligent, more driven and more entrepreneurial than them. It is not unusual for ambitious junior managers to exhibit a willingness and ability to take initiative; this is 
sometimes looked upon with hostility by their senior colleagues. Nevertheless, good management surely requires appointment committees to always attempt to appoint people who are 'better' than the appointers. This is so for several reasons. First, the relevant organisation presumably would run better if the most competent persons were to be appointed to staff positions. Second, the appointment of the most competent person to a position would also enhance the position of the appointers because they would be able to claim, quite justifiably, that they (i) have the ability to match peoples' qualifications with occupational roles, and (ii) are able to manage an organisation which runs smoothly

In this context, it is also important to emphasise that senior managers should always give credit to junior colleagues whose job-related achievements have enhanced the reputation of their organisations. Indeed, it is an inexcusable, but common, mistake for senior managers to arrogate to themselves the achievements of their junior colleagues without giving appropriate credit to those who actually engineered these achievements. Indeed, the failure by senior management to acknowledge the achievements of their employees leads to low staff morale and distrust between senior managers and their junior colleagues.

There have been notable attempts to ensure that jobs and competences are linked. This linkage is required either by legislation or by university legislation/regulations, or by the enterprise bargaining agreement (EBA) rules which require positions to be advertised. However, my experience suggests, that, if positions are advertised, you often get the person you do not want. Admittedly, this is an anecdotal argument; nevertheless this outcome may, at times, be a consequence of the involvement in the appointment process of the organisation's Human Resources and equity committees which have little knowledge of the skills which are sought in an appointee. In many cases, these committees are merely interested in ensuring that procedural safeguards are respected and processes followed, or that the organisation's workforce statistically reflects the total numerical strength of all groups in society. In such circumstances the appointee is almost always a compromise appointment and may not be the 'best' or most 'suitable' person for the job.

\section{The Centralisation of Resources, Services and Decision-Making of the Organisation}

Centralisation "means that formal decision-making authority is held by a small group of people, typically those at the top of the organisational hierarchy" (McShane \& Travaglione, 451). However, the concentration of decision-making in a few hands is merely one manifestation of 'centralisation'. Indeed, centralised decisionmaking is often coupled with the centralisation of the organisation's relevant resources and services in order to facilitate the management by decision-makers and to achieve better oversight, administrative convenience, and costs-savings (by avoiding duplication).

However, in doing so, decision-makers overlook the costs associated with centralisation, especially nonmonetary costs, such as deterioration in staff morale. This may happen because centralisation of resources, services and decision-making typically deprives staff members of the means to control their own professional destiny and inhibits their willingness to take initiative.

The administration of an organisation's divisions is made more difficult because centralisation typically involves the removal of administrative staff members from their previously decentralised 'habitat' and places them in a central office where they are part of a common pool of service providers. Hence, the administration officer allocated to serve a unit of the organisation often would not know the people they are dealing with and would be emotionally removed from, or perhaps even be disinterested in, that unit. Consequently, there is a spectacular disconnect between the administrator and those who are administered.

In this context, I have heard it said that centralised bureaucracies exist to ensure that people are prevented from doing their jobs! This is well known in a university environment, where the cumbersome and extensive research and administrative bureaucracies consist of people who impose a multitude of administrative requirements upon academics, such as numerous form-filling and reporting obligations. Richard Hil, in Whackademia: An Insider's Account of the Troubled University lists some of the forms, which he claims are "a distillation of only a tiny fraction of the suffocating miasma billowing out from these institutions" (Hil, 173- 
174). Such bureaucratic requirements inhibit academics from doing the research they are expected to undertake.

An example from a different sector is the Queensland Health payroll debacle (Madigan, Vogler \& Stolz: www.theaustralian.com.au/national-affairs/state-politics/queensland-payroll-debacle-to-cost-taxpayers-12billion/story-e6frgczx-1226691935660). In Queensland, payment of all health professionals was centralised for reasons of convenience. The financial officers who had been posted to different sections and hospitals were removed from their previously-held positions. The shambolic implementation of this scheme resulted in an inadequate and unreliable payment system for the health sector in Queensland. In New Zealand, the implementation of Novapay's $\$ 30$ million computer payroll system resulted in similar problems for the Ministry of Education. The computer system controlled a fortnightly national education payroll for more than 90,000 people. For many weeks, Novapay made incorrect or no payments to school staff, in some instances trebling the work of the local payroll administrators. This resulted in financial problems for some educators and enormous stress for those within the system (http://www.odt.co.nz/opinion/editorial/234463).

Academics would also be familiar with the pompous desire of university officials and central committees to develop new policies on every conceivable topic. This desire often manifests itself in an unending process the purpose of which is to develop the 'best' possible policy with regard to a particular topic. Indeed, it is not unusual for universities to have a policy on the development of policies! University committees spend much time and effort developing the 'best' possible policy they can develop, a kind of Rolls Royce policy which encapsulates the best practice from around the world. However, once this Rolls Royce policy is adopted, the policy is treated with benign neglect by the university community or very few resources are allocated to the implementation and monitoring of the policy, leading to a failure to achieve the desired results. The committees which draft these policies do not seem to understand that the implementation of their new policies typically increases the burdens placed upon academic staff members who are deemed to possess an infinite appetite for absorbing new policies. Perhaps there should be a policy on the removal of policies? Some governments have done this by introducing "one-in, one-out" rules for departments proposing new regulatory regimes.

Centralisation is essentially a manifestation of micro-management. It is based on the assumption that noone but senior management can be trusted and that all power has to be centralised in the hands of a few. This management style stifles innovation and creates low staff morale within organisations.

In a centralised system, little of substance can be done without applying to various committees that inevitably take a long time to make a decision. In my experience, in such a system, the best operators are those who courageously undertake the work that needs to be done before they officially ask for permission to proceed. Once the work is successfully completed, they would then ask for permission to undertake what had already been accomplished.

\section{Restructurings and Change Management Overload}

It would appear to an interested observer that in universities there is a never ending pursuit of restructuring, followed by change management. The centralisation of resources and services is often the aim of restructuring projects. I am not referring to gradual or incremental changes but to major restructurings and change management programmes, often spearheaded by a change management consultancy, costing millions of dollars and requiring an enormous amount of time and commitment, especially on the part of senior academics. Senior university leaders appear to believe that, in order to make an impact, they need to restructure their organisations in their own image, without considering the culture of the university or the expectations of relevant staff members and students. These leaders are typically obsessed with their self-importance and imagined infallibility and they exude misplaced overconfidence. I even know of at least one Vice-Chancellor and President of an Australian university, who established an academic department that was clearly not supported by the market and, hence, had very few students, but boasted impressive facilities and involved the recruitment of expensive staff members. 
I have worked at universities that embarked on a massive restructuring programme, which aimed at introducing new and efficient programmes at the university. The results were vacuous, unpopular, and even intrusive. These new programmes provided for centralised services, ranging from standardising travel applications to computerising essential university functions. Each week for about two years, there were endless meetings during which the attendees were bombarded with brightly coloured presentations slides indicating the start and end dates of programmes, implementation periods, review periods, procedures, exemptions, and sundry other detail. Soon afterwards, a new senior leadership was appointed and the project was abandoned. In its place a new process of massive change and restructuring started, leading to change fatigue among staff.

The restructuring project was sometimes associated with the making of 'ad hoc' management decisions which adversely impacted on the roles of academic administrators. For example, I recall that, at least on one occasion, as a consequence of restructuring exercises, even senior people, whilst being allowed to retain their title, for example, the title of Pro Vice Chancellor, were stripped of all their authority because the university leaders wanted to restructure the university without Pro Vice Chancellors. Although senior management may have a good reason to pursue a restructure, it is humiliating not to allow people already appointed to do their job during the restructuring process. Hence, these people were Pro Vice Chancellors in name only and not in reality. Of course, this type of restructuring was often an attempt by the university to centralise power into the hands of a few senior managers. Also, such practice does not empower staff members to excel in their professional activities, to enhance the reputation of their units and to maintain their viability.

These restructurings, followed by change management programmes, are very costly, not just in terms of their development and implementation, but also because there is usually also an enormous opportunity cost since academics' involvement in change management processes inevitably impacts upon the real function of universities, i.e. teaching and research. There is no doubt that change management overload exists and that people tire of constant change, especially if senior management practice micro-management and reach into areas which traditionally come within the domain of more junior members of staff.

\section{Other Mismanagement Strategies in Brief}

\subsection{Uses and Abuses of Committees}

Committees could be used to manage or mismanage an organisation. Indeed, a good manager may well want to send issues, proposals or concerns to a committee for discussion if they do not want a decision to be made at all. This reminds me of Charles F Kettering who reportedly stated that, "If you want to kill any idea in the world, get a committee working on it." Committees are often glorious talk fests which keep laborious minutes and waste hours. A variant of this strategy involves the stacking of committees in order to achieve a pre-determined outcome. If no outcome is wanted, the committee will not be stacked and it would be in the interests of managers to ensure that the committee keeps meeting with no outcome in sight.

Alternatively, a matter might be sent to a committee because the manager is incapable of making decisions or they expect the committee to support the manager's proposed action. Occasionally, if not often, managers may be scared of the ramifications of their decisions. If so, a manager usually gives in to irrational sections of the workforce who merely want to retain their privileges.

\subsection{Penalising Staff Members who do the Right Thing}

I have worked in organisations that penalised hard-working people for complaining about the unwillingness of some employees to do their job. In particular, I know of people who, during a sabbatical period, did absolutely no work as was expected of them and, nevertheless, were rewarded by senior management. In addition, their supervisors, who insisted on the proper use of sabbatical leave privileges, were castigated for 'bullying' their incompetent, lazy or opportunistic colleagues. At the same time, there exists a 'dobbing in' culture whereby lazy staff members complain about their supervisors for requiring them to work. 
'Bullying' is a code word, often embraced by managers who have been appointed to their level of incompetence. I recall a memorable event: on one occasion, a staff member answered the "what are your career aspirations" question in a Professional Employment Survey (PES) report by stating "None of your business". When the supervisor complained about this decidedly unprofessional behaviour, they were reprimanded by their own managers for bullying the employee!

\subsection{Spend Money like a Drunken Sailor}

In my experience, there is often profligate spending by senior managers. Of course, it is always easy to spend someone else's money, especially if the managers feel that there is no or limited accountability. I have heard of managers whose expense accounts exceeded their salaries and who were able to nurture their spending habits for years with impunity. Although these managers would always emphasise the importance of 'budgeting', in reality they never cared about living within their means. Obviously, such uncontrolled spending sets a bad example and generates jealousy.

It is not unusual for people who have achieved 'powerful' positions in organisations to become profligate spenders. I have personally heard some top managers say that 'they are surprised that they have so much power'. Such a statement is problematic because a person who desperately seeks power should never be given power since they will merely manage organisations in order to serve their own interests, as opposed to the interests of the organization.

\section{Conclusion}

In this paper, I have described examples of how an organisation could be mismanaged. In concentrating on four interrelated practices which, in my opinion, will result in mismanagement, I sought to indicate what managers should not do in order to reduce the risk of managing their organisations badly. Although this paper does not prescribe what has to be done in order to successfully manage an organisation, it is important to stress that good management supports their staff members, ensuring there are opportunities for their selfenhancement, coupled with a realisation that they need to take responsibility for their own actions. This requires the adoption of sound management practices and the pursuit of excellence.

\section{Acknowledgements}

The author gratefully acknowledges the comments received from Dr. John Selby, Ms Annelies Moens and Dr. Peter Gillies on earlier versions of this paper.

\section{References}

Chynoweth, Carly (2014). Be the power behind the throne. The Sunday Times, 6 July 2014, Section 7, 2.

Chynoweth, Carly (2014). Too much talent kills team spirit. The Sunday Times, 6 July 2014, Section 7, 3.

Collins, Roger (1993). Effective Management. North Ryde, NSW: CCH International.

Forsyth, Hannah (1 October 2014). How leaders lost their way. The Australian. Higher Education, 36.

Gettler, Leon (September 2014). Feeling Smarter. Management Today, 10-11.

Hanson, Peter (1986). The Joy of Stress, Sydney: Pan Books.

Hil, Richard (2012). Whackademia. An Insider's Account of the Troubled University. Sydney: Newsouth.

Johnson, Samuel (1759). The History of Rasselas, Prince of Abyssinia. London: Dodsley. Reprinted London: Limbird, 1824.

McAdam, Neil (2006). Situational Stress and Restriction of Stylistic Repertoire in High Potential Managerial Aspirants: Implications for the Implementation of the 'New Organization'. Journal of Management and Organization 12(1), 40-67. 
McShane, Steven \& Travaglione, Tony (2007). Organisational Behaviour on the Pacific Rim (2nd ed.), North Ryde: McGraw-Hill Irwin.

Message, John (1986). A Practical Guide to Stress and Its Management, Hutchinson of Australia.

Moens, Gabriël A. (2002). Preferential Admission Programs in Professional Schools: Defunis, Bakke, and Grutter. Loyola Law Review, 48, 411-503.

Needham, Alix (1996). The Stress Management Book, East Roseville, NSW: Simon \& Schuster Australia.

Peter, Laurence J. and Hull, Raymond (1972). The Peter Principle, New York: Bantam, New York.

Peter, Laurence J. (1973). The Peter Prescription: How to Make Things Go Right, New York: Bantam.

Peter, Laurence J. (1985). Why Things Go Wrong or The Peter Principle Revisited, New York: William Morrow and Company, Inc.

Pirihi, Lorraine. "Managing Stress - Hire the Right People", www.g55.in/business-finance/article1606.html (accessed on Sunday, 21 September 2014).

Redish, Martin H. (1974). Preferential Law School Admissions and the Equal Protection Clause: An Analysis of the Competing Arguments. University of California Los Angeles Law Review 22, 343-400.

Salovey, Peter and John D. Mayer (1990). Emotional Intelligence. Imagination, Cognition, and Personality, 9(3), 185211.

Stone, Raymond J. (1995). Human Resource Management (3rd ed.), Brisbane: John Wiley \& Sons.

Summers, Clyde W. (1970). Preferential Admissions: An Unreal Solution to a Real Problem. University of Toledo Law Review 2, 377-402.

http://www.evancarmichael.com/Human-Resources/840/Stress-and-Peter-Principle.html (accessed on Saturday, 4 October 2014).

http://www.theaustralian.com.au/national-affairs/state-politics/queensland-payroll-debacle-to-cost-taxpayers-12billion/story-e6frgczx-1226691935660 (accessed on Saturday, 4 October 2014). 